\title{
Amorf dentritik agatta quasi kristallerin fraktal büyümesi
}

\author{
Mehmet BAYIRLI* \\ Balıkesir Üniversitesi, Fen Edebiyat ve Fakültesi, Fizik Bölümü, Çă̆ış Kampusu, Balıkesir. \\ Gelis Tarihi (Recived Date): 30.01 .2017 \\ Kabul Tarihi (Accepted Date): 12.06.2017
}

\section{Özet}

Bu çalışmada; katı-katı faz geçişiyle quasi-kristallerin fraktal büyümesi sunulmaktadır. Yüksek dăgılıma sahip rastgele dallanarak kristalleșmiș fraktal büyüme fazı amorf dendritik agatlarda gözlemlenmiştir. Sirası ile, yoğunluk korelasyon fonksiyon üssü mangan kristalleri için yaklaşık olarak $\alpha \sim 0.308-0.342$ fraktal boyut değerleri $D \sim$ 1.238-1.626 hesaplanmıştır. Dentritik agat sisteminin bileşenleri sicaklık ve konsantrasyon gradiyentlerinin durumuna göre değişkenlik gösterir. Sicaklık arttıkça mangan oksit çekirdeğe sızmakta, sicaklık azaldıkça ise mangan oksit katılaşıp kristalleşmektedir. Bu numunede kristal büyüme quasi statik limitte ve difüzyonla sinırlı koşullarda gerçekleşmektedir. Sonuçlar; difüzyonla sınırlı kümeleşme modeli ile uyum göstermektedir. Fraktal büyümenin gözlemlendiği diğer sistemlerle karşılaştırllarak oluşum mekanizmaları tartışılmıştır.

Anahtar kelimeler: Amorf dendritik agat, fraktal, difüzyonla sınırlı kümeleşme(DLA).

\section{Fractal growth of quasi crystals in the amorphous dendritic agate}

\begin{abstract}
In this study, fractal growth of quasi-crystals is presented by solid-solid phase transition. The randomly branched crystallized and quasi fractal growth phase with high distribution was observed in amorphous dendritic agates. The critical exponent values of correlation function and the fractal dimensions were approximately calculated as $\alpha \sim 0.308-0.342$ and $D \sim 1.238-1.626$ and for manganese crystals, respectively. The components of the dendritic agate system vary according to the state of the temperature and concentration gradients. As temperature increases, manganese oxide seeps into the core. As temperature decreases, manganese oxide solidifies and crystallizes. In this
\end{abstract}

\footnotetext{
*Mehmet BAYIRLI, drbayirli@gmail.com, http://orcid.org/0000-0002-7775-0251
} 
sample, crystal growth occurs at quasi-static limit and diffusion limited conditions. Results; It is in agreement with the diffusion-limited aggregation model. The formation mechanisms have been discussed in comparison with other systems in which fractal growth is observed.

Keywords: Amorphous dendritic agate, fractals, diffusion limited aggregation (DLA).

\section{Giriş}

Dallanarak doku oluşturan mangan minerallerinde çok nadir karbonat ve oksitler kimyasal difüzyon oranlarına göre kristalleşme kinetiklerinin yüksek olduğu bölgelerde kristalleşirler [1, 2]. Bu durum, genellikle çevre koşulları, termal ve konsantrasyon gradiyentleri, yavaş gelişen difüzyonla ile karakterize edilmektedir [3, 4]. Doğal örnekler olarak volkanik kayalarda, manyezit cevherinde, volkanik tüf ve zeolit yüzeylerinde veya iç bölgelerinde gözlenmektedir [2-7].

Jeolojik oluşumlardan biri de amorf dendritik ADA dır. ADA üzerinde kahverengiden siyaha dönüşen ve "dendirt" olarak bilinen ağaç ya da eğrelti otuna benzemesinden dolayı kolay fark edilen Kalsedon Quarz, beyazımsı ve grinin çeşitlerini barından, renksiz ve şeffaf yapıya sahiptir. Mosh ölçeği 6.5 ve 7.0 , spesifik gravity 2.59 ve 2.67 ve yansıma indeksi 1.530 ve 1.540 aralığında değişmektedir. Yarılma özelliğine sahip değildir. Ancak dallanan dendiritler amorf DA ara yüzeyinde ve hacimsel olarak içe doğru büyüme özelliği gösterir. ADA'nın temel yapısı silikon dioksittir $\left(\mathrm{SiO}_{2}\right)$. Üzeri ve iç bölgeleri siyah $(\mathrm{MnO})$ ve bazen kırmızı $\left(\mathrm{Fe}_{2} \mathrm{O}_{3}\right)$ simetrik geometrik şekiller içermesinden dolayı işlenerek süs taşı olarak kullanılmakta ve yarı değerli taş grubu içinde incelenmektedir. Ancak dendritik yapıların makroskobik geometrik özelliklerini belirleyen bir çalışma günümüze kadar yapılmamıştır [5].

Difüzyonla sınırlı kümeleşme (Difusion-Limited Aggregation (DLA)) modeli, 1981 yılında Witten ve Sander tarafından önerilen ve numunelerdeki katı-katı faz sürecinin en önemli özelliklerinden bazısını tanımlayan basit bir modeldir [9, 10]. Konsantrasyon C olmak üzere Laplace denklemi $\left(\nabla^{2} \mathrm{C}=0\right)$ ile katı faz büyümesi nümerik yaklaşımla belirlenebilir. İki ya da üç boyutlu kapalı örgüde DLA modeli algoritması kullanılarak belirlenen sınır şartları, üretilen dendritik desen temsilleri harmonik sınır koşulları ile ilgilidir [10]. Doğada fraktal yapıların tanımlanması için DLA modelinin geçerliliği jeolojik minerallerin kristalleşmesinde ve hidrodinamik, elektro birikme, püskürtülerek birikme ve elektrostatik boşalma gibi bazı deneysel araştırmalarda gösterilmiştir [2, 7, $8,10]$. Ancak bu model kristalin katı fazının mikro yapısından ziyade makroskobik geometrik yapısını açıklamaktadır.

$\mathrm{Bu}$ çalışmada ADA içinde büyüyen, mangan kristali katı fazının makroskobik geometrisi ölçekleme teorisi kullanılarak incelenmiştir. Ayrıca, numunedeki mangan kristallerinin DLA temsili yapılar ile karşılaştırılmasının sonuçları tartışılmaktadır.

\section{Materyal ve yöntem}

Bu çalışmada kullanılan ADA numunesi, Balıkesir ili, merkez Çağış beldesinin yaklaşık $1 \mathrm{~km}$ güneyinde bulunan bentonit üretim ocağından alınmıştır. Bentonit ocağının 
koordinat $1 \mathrm{~K} 39^{0} 30^{\prime} 07^{\prime \prime}$ ve D $28^{0} 00^{\prime} 28^{\prime \prime}$ olarak nevigasyon cihazı (TOMTOM XXLCE N14644) ile belirlenmiştir. Yaklaşık bir küresel yapıya sahip numune, iki tarafından rastgele kesilerek ortasından bir dilim oluşturulmuştur. Katı mangan kristallerinin dilimin içinde rastgele dağglmış olduğu ve küresel yüzeyden merkeze doğru rastgele yönelimli olduğu gözlemlenmiştir. Numunenin ön yüzey görünümü fotoğraf makinesi (CANON EOS 1100D) kullanılarak görüntülenmiş ve bilgisayar ortamına taşınmıştır. Bunlardan seçilen tipik bir görüntü Şekil 1(a)'da gösterilmektedir.

\section{Bulgular}

DLA algoritması kullanılarak üretilen ve temsili katı kristal yapıları ADA daki katı faz kristalleri ile karşılaştırmak için yoğunluk korelasyon fonksiyon üssü değeri ve fraktal boyut değerleri hesaplandı [8-11]. Görüntü işlemcisi ile Şekil 1(a) ve 1(b)'de sunulan görüntüler imageJ programı ile dijitlenmiş ve ölçeklenmiştir [12]. 256x256 piksel boyutlu kare örgü (bit map) elde etmek için logaritmik olarak alt tabaka belirlenmiştir. Daha sonra mangan kristal parçacıklarını temsil eden siyah pikseller bir (1), alt tabayı temsil eden beyaz pikseller sıfır (0) alınarak hesaplamalar yapılmıştır. Dendirt dal uzunlukları 72 piksel ile 654 piksel arasında değişmektedir.

Görüntüden seçilen farklı kristal büyümeleri yoğunluk korelasyon fonksiyonu $\mathrm{C}(\delta)$ değeri $\delta \rightarrow 0$ limitinde;

$\mathrm{C}(\delta) \propto \delta^{-\alpha}$

bağıntısı kullanılarak hesaplanmıştır [8-12]. Burada $\alpha$ değeri kristal büyümeyi belirleyen kritik üs değeridir. Yoğunluk korelasyon fonksiyonu ve örgü boyutunun log $\mathrm{C}(\delta)-\log (\delta)$ grafiğinin eğiminde kritik üs değeri hesaplanmıştır. Söz konusu grafik Şekil 3(a) gösterilmiştir. Küresel yapılı ADA içine doğru sızan ve kristalleşen mangan yapılarının kritik üs değeri 0.308-0.342 aralığında değişmektedir. Ayrıca diğer örneklerin fit aralıkları ve kritik üs değerleri Tablo 1 de özetlenerek gösterilmiştir. DLA modeli ile üretilen dendritik katı fazının kritik üs değeri iki boyutta 0,34 olarak rapor edilmiştir $[9,10]$.

Ayrıca, seçilen numunelerin fraktal boyut değerleri hesaplanmıştır. Mangan kristallerini temsil eden siyah piksellerin sayısı n $(\delta)$ ve her bir piksel boyutu $\delta$ olmak üzere;

$\mathrm{N}(\delta) \propto \delta^{-\mathrm{D}}$

bağıntısı kullanılmıştır [7-9, 11]. Buradaki D katı fazdaki kristalin fraktal boyut değeridir. Mangan kristalini temsil eden piksellerin sayıs1, örgü boyutunun $\log n(\delta)-\log$ $(1 / \delta)$ grafiğinin eğiminden fraktal boyut değeri hesaplanmıştır. Ayrıca, korelasyon yoğunluk fonksiyon üs değeri ile fraktal boyut arasında ölçekleme teorisine göre;

$\mathrm{D}=\mathrm{d}-\alpha$

ilişkisi vardır [9, 10]. Burada $\mathrm{d}=2$ olmak üzere iki boyutlu uzay için Oklit boyut değeridir. Denklem 1 ve 2 de hesaplanan değerler, denklem 3'den elde edilen ile karşılaştırılmış ve yaklaşık olarak uyum içerisinde olduğu gözlemlenmiştir. Manganın kristalimsi fazının fraktal boyut değeri 1.238-1.626 aralığında değişmektedir. Ayrıca fraktal boyut değerleri Tablo 1'de gösterilmiştir. Daha önce yapılan benzer 
çalışmalarda, mangan kristallerinin farklı yapılar üzerindeki fraktal boyut değerleri rapor edilmiştir. Manyezit cevherinin yüzeyinden seçilen mangan dendritleri için fraktal boyut değerleri 1.39-1.65 ve DLA modeli ile üretilen on temsili simülasyonun ortalama fraktal boyut değeri 1.47-1.63 olarak hesaplanmıştır [2, 8, 12]. $\mathrm{Ng}$ ve Teh, quarz üzerinde mangan kristallerinin fraktal boyutunu, ortalama fraktal boyut değerini 1.75 olarak hesaplamıştır [7]. Chopard ve arkadaşları ise fraktal boyut değerini

kireç taşının yüzeyindekiler için 1.78 ve kuvars yüzeyindekiler için 1.51 olarak belirlemiştir [11]. Merdan ve Bayirli'nın manyezit cevher yüzeyindeki mangan dendritleri için yaptıkları çalışmada fraktal boyut 1.61-1.88 arasında değerler almaktadır $[8,13]$. Kısa ve kalın dallara sahip dendirt desenlerinin fraktal boyut değeri, ince ve uzun dendirt desenlerinin dallarına kıyasla genellikle daha büyük değerlere sahiptir. Grafikteki hata sütunları, çeşitli yönelimlerdeki dijitleme tekrarlarından gerçekleşmiş olduğu tahmin edilmektedir. Ayrıca, metodun doğruluğunu test için Sierpinski Gasket'in bilinen bir görüntüsü için \% 1 doğrulukla hesaplanmıştır.

Şekil 1(a) ve 1(b) görüntülerindeki farkl1lık format değişikliğindendir. Şekil 1(a) TİFF ve Şekil 1(b) ise BMP formatındadır. Yaklaşık fraktal büyüme doğrultusu Şekil 1(b) üzerinde oklarla gösterilmektedir.
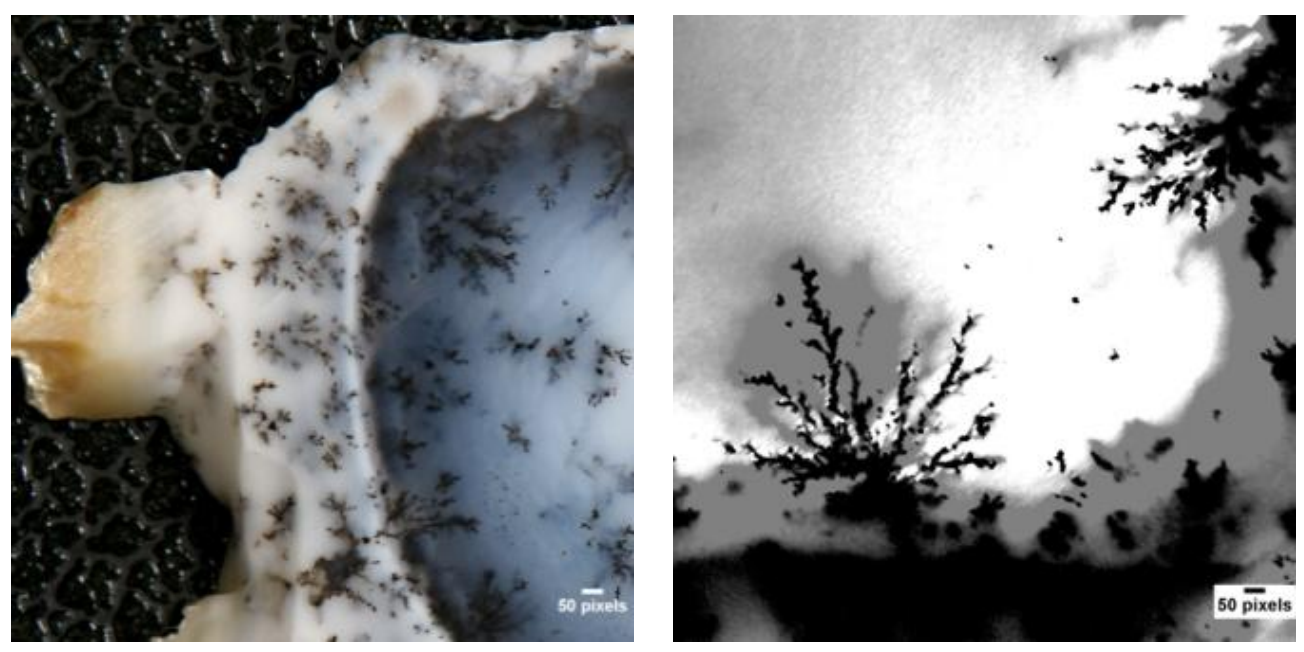

Şekil 1. (a) Tipik iki tarafından kesilmiş amorf ADA numunesi dilimi ve (b) Yaklaşık küresel ADA numunesinin yüzeyden merkeze doğru mangan katı fazının fraktal büyüme görüntüsü.

Tablo 1. DA numene içindeki fraktal büyüme ile oluşan mangan quasi kristallerinin fit aralıkları, kritik üs ve fraktal boyut değerleri.

\begin{tabular}{cccc}
\hline Örnekler & Fit Aralı̆̆ & Kritik Üs $(\alpha)$ & Fraktal Boyut (D) \\
\hline ADA-1 & $6-22$ & - & $0.366 \pm 0.011$ \\
ADA-2 & $6-22$ & - & $1.238 \pm 0.021$ \\
ADA-3 & $6-22$ & $0.342 \pm 0.003$ & $1.626 \pm 0.006$ \\
ADA-4-DLA & $4-16$ & $0.308 \pm 0.007$ & $1.626 \pm 0.007$ \\
ADA-5-DLA & $18-36$ & $0.314 \pm 0.005$ & $1.687 \pm 0.011$ \\
\hline
\end{tabular}


Tablo 1 de gösterilen ADA-1 ve 2 yapıları dendritik yapıda olmayıp, yoğun benek şeklinde desen oluşturmaktadır. Ancak ADA-3, 4 ve 5 DLA modeli ile elde edilen görüntüler dendritik yapıdadırlar. Dendritik yapının oluştuğu bölgede ise yüzey anizotropik bir etkinin olduğunu göstermektedir.

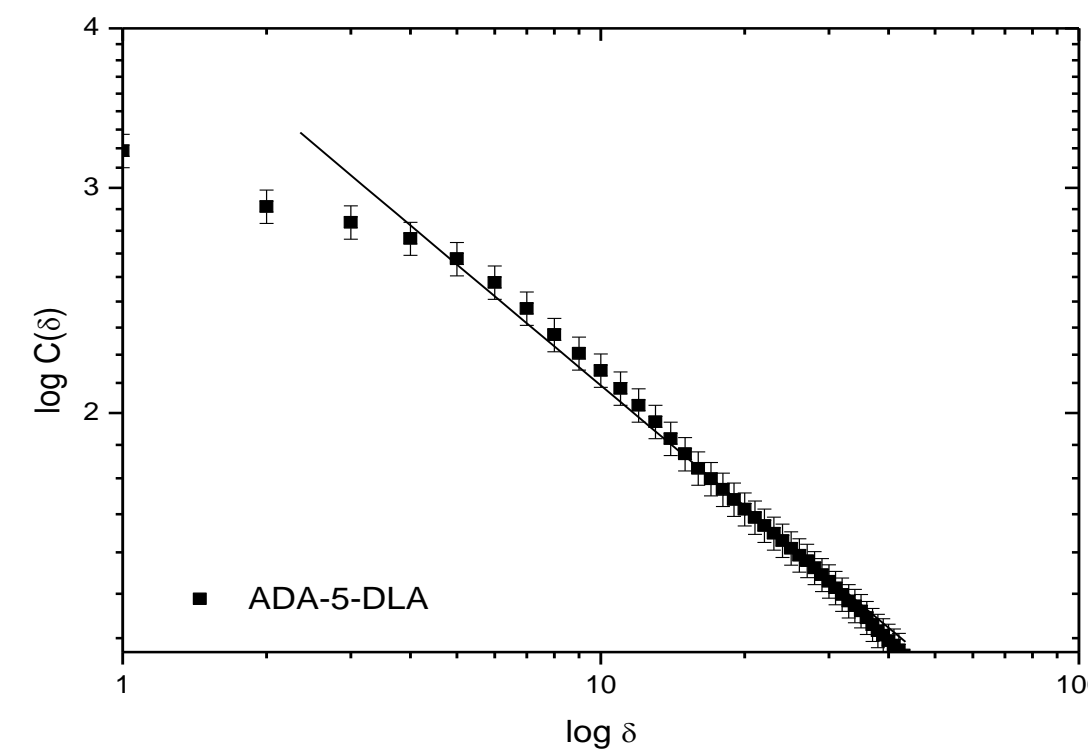

(a)

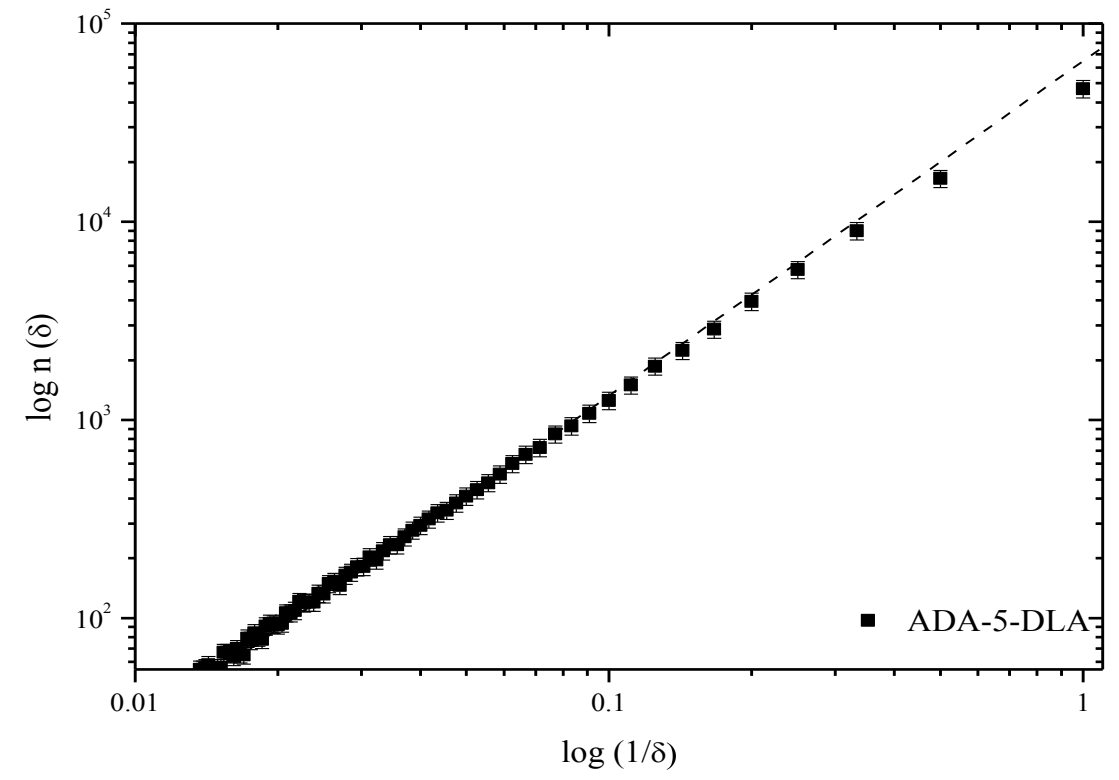

(b)

Şekil 2. (a) ADA-5-DLA numunesi için $\log \mathrm{C}(\delta)-\log (\delta)$ grafiği ve (b) Aynı numune için $\log N(\delta)-\log (1 / \delta)$ grafiği.

Farklı geometrik yapılı (maki türü) kristal desenleri, ADA küresel yüzeyinden hacimsel olarak içe doğru ve ara yüzeylerde birikerek veya çökelerek birbirlerine göre farklı yönelimli mangan kristallerinin kristalleşen katı fazı görüntüsü sergilediği gözlemlenmiştir. Bu katı-katı faz geçişinde izotropik yüzey geriliminin etkisi oldukça küçük olabilir. Çünkü manganın jeolojik yeni koşullarda büyüme yönleri rastgele dağılımlı polikristalik özellik göstermektedir.

DLA fraktal büyümesinin orijini, Mullis-Sekarka düzensizliğinin bir örneğidir. Bir dalın tipi ne kadar ilerlemiş olursa, o kadar etkili bir şekilde difüzyona uğrayan parçacıklar 
yakalanır ve kristal küme o kadar hızlı bir şekilde büyür. Bu aşırı soğumuş eriyikler, katılaşmaya doğru yönelimin bir analojisidir. Ĕger ara yüzeyin herhangi bir 1lık noktasından daha soğuk noktasına doğru akıntı olursa, sıvının katı faza dönüşmesi daha hızlı ve rasgele ilerleme olduğunu gösterir. Bir farkla benzeşen mekanizma, mangan fraktal büyüme olgusuna uyarlanabilir. Jeolojik oluşum esnasında kristalleşme daha sıcak bölgede başlar ve ara yüzeyden hareketler ile daha soğuk bölgeye doğru yönelir. Büyük bir olasılıkla kararsızlık ve konsantrasyon gradiyentlerinin sınırlı büyümenin olduğu bölgede ortaya çıkan hidro termal sıvısının karışımının izotermal katılaşmadaki etkileri, kristal büyümeyi belirler. Benzer dendritik büyüme çinko, elektro depozitle üretilen silisyum, germanyum ve bakır içerikli filmler ile ilgili deneysel çalışmalarda da gözlenmiştir [14-16].

\section{Sonuç ve öneriler}

ADA sisteminin ana bileşenleri silisyum dioksit $\left(\mathrm{SiO}_{2}\right)$, ikincil katkı olarak mangan oksit $(\mathrm{MnO})$ ve eser maddeler olup bunların miktarları farklıdır. Eğer ortam sıcaklığı amorf-katı sıcaklığından daha büyükse mangan oksidin çekirdekleşmesi ya da kristalleşmesi daha sıcak yerde başlar. Silisyum dioksitin kristalleşme fazı da gerçekleşirken, konsantrasyon gradiyenti değerinin dalgalanmasından dolayı ADA'yı saran hidro termal sıvı içindeki mangan oksit atomları içeriye sızar. Sıcaklığın azalması ve içyapıdaki anizotropik özellik ise mangan oksidin katılaşmasına ve çekirdekleşmesine sebep olur. Bundan dolayı ADA içindeki mangan kristalleri ölçek değişmezliğine sahip olur. Ancak kristalleşme sadece yüzey difüzyonu ile gerçekleştiği sonucuna varmak yanlış olabilir. Gözlemler kristal büyümenin quasi-statik limitte difüzyonla sınırlı koşullarda gerçekleştiğini göstermektedir.

Doğal olarak, katı-katı faz geçişinde birçok ilave faktörlerin sonuçları beklenmeyen ilave ek faktörlerin sonuçlarını etkilemesi beklenir. Kristal fazının öz hacmi amorf durumdan daha küçüktür. Bundan dolayı uzun aralık (long-range) elastik kuvvetler büyüme esnasında ortaya çıkar. Bu kuvvetlerin kendileri kararsızlığı ortaya çıkarmayabilir. Ancak fraktal büyümede önemli rol oynayabilir. Genellikle ADA'y1 saran hidro termal sıvıdaki kirliliğin oluşturduğu heterojenlik, gerçek ara yüzeyin şeklini belirler. Ancak, sızma benzeri rejimde eşik değerine sahip olsa bile, daha sonraki heterojen yapıya öncülük yapması beklenmemelidir.

Bu çalışmada MnO'un yüzeysel ve hacimsel kristalleşme fazının fraktal desen büyümeli doğal bir örneği sunulmuştur. Bu oluşumların bazı makroskobik geometrik özelliklerini açıklamak için DLA modeli kullanılabilir. Bu gözlem, jeolojik ADA içinde fiziksel katıkatı faz geçişi makroskobik olarak belirlenebilen bir durumdur. Bu ADA numunesinde düzenli kristalden ziyade rastgele yönelimli içsel anizotropiden dolayı fraktal yap1 gözlemlenmektedir. Daha önce yapılan deneysel çalışmalarda, fraktal büyümenin diğer tiplerinde fraktal desenler uzun süreli difüzyon ve küçük anizotropili difüzyonla sınırlandırılmış her bölgede bu yapının oluşabileceğini göstermiştir.

\section{Teșekkür}

Sayın Fatma YIKAR'a katkılarından dolayı teşekkür ederim. 


\section{Kaynakça}

[1] Barton, P.B., Ore textures: problems and opportunities, Mineralogical Magazine, 55, 303-315, (1991).

[2] Bayirli, M. ve Ozbey, T., Numerical approaches about the morphological description parameters for the manganese deposits on the magnesite ore surface, Zeitschrift for Natuforchhung Section A-A Journal of Physical Sciences, 68a, 405-411, (2013).

[3] Swartzlow, C., Two dimensional dendrites and their origin, Geology Mineralogical Society of America, 9, 403-411, (1934).

[4] García-Ruiz, J.M., Otálora, F., Sanchez-Navas, A. ve Higes-Rolando, F., The formation of manganese dendrites as the material record of flow structures In Fractals and Dynamics Systems in Geosciences, Edited by J. H. Kruhl, Springer Verlag, 307, (1994).

[5] Dendritic agate gemstone information, http://www.gemselect.com/gem_info/dendritic-agata, (27.01.2017).

[6] Xu, H., Chen, T. ve Konishi, H., HRTEM investigation of trilling todorokite and nano-phase Mn-oxides in manganese dendrites, American Mineralogist, 95, 556-562, (2010).

[7] Ng, T.F. ve Teh, G.H., Fractal and shape analyses of manganese dendrites on vein quartz, Geological Society of Malaysia, 55, 73-79, (2009).

[8] Bayirli, M. ve Kockar, H., A Numerical application using diffusion-limited aggregation for the manganese dendrites, Zeitschrift for Natuforchhung Section A-A Journal of Physical Sciences, 65a, 777-780, (2010).

[9] Witten, T.A. ve Sander, L.M., Diffusion-limited aggregation, a kinetic phenomenon, Physical Review Letter, 47, 19, (1981).

[10] Özbey, T. ve Bayırlı M., Mangan sıvamaları ve DLA modeli için sayısal bir hesaplama, Balıkesir Üniversitesi Fen Bilimleri Enstitüsü Dergisi, 18, 1, 5866, (2015).

[11] Chopard, B., Herrmann, H. ve Vicseck, T., Structure and growth mechanism of mineral dendrites, Nature, 353, 409-412, (1991).

[12] Schneider, C.A., Rasband, W.S. ve Eliceiri K.W., NIH Image to ImageJ: 25 years of image analysis, Nature Methods 9, 671-675 (2012).

[13] Merdan, Z. ve Bayirli, M., Computation of the fractal pattern in manganese dendrites, Chinese Physic Letters, 22, 8, 2112-2115, (2005).

[14] Matsushitai, M., Hayakawa, Y. ve Sawada, Y., Fractal structures and cluster statistic of zinc-metal trees deposited on a line electrode, Physical Review A, 32, 3814-3816, (1985).

[15] Radnoczi, G., Vicsek, T., Sander, L.M. ve Grier, D., Growth of fractal crystals in amorphous $\mathrm{GeSe}_{2}$ films, Physical Review, 35, 9, 4012-4015, (1987).

[16] Koçkar, H., Bayırlı, M. ve Alper, M., A new example of the diffusion-limited aggregation: Ni-Cu film patterns, Applied Surface Science, 256, 9, 2995-2999, (2010). 